\title{
Violências e riscos psicossociais: narrativas de adolescentes abrigados em Unidades de Acolhimento do Rio de Janeiro, Brasil
}

\author{
Violence and psychosocial risks: narratives of adolescents \\ living in shelters in Rio de Janeiro, Brazil
}

\begin{abstract}
Adriana Pedreira Botelho ${ }^{1}$
Mayara Cristina Muniz Bastos Moraes ${ }^{1}$

Ligia Costa Leite ${ }^{1}$
\end{abstract}

${ }^{1}$ Instituto de Psiquiatria, Universidade Federal do Rio de Janeiro. Av. Venceslau Brás 71 fundos, Campus Praia Vermelha. 22290-140 Rio de Janeiro RJ Brasil. adrianabotelhopsi@ gmail.com

\begin{abstract}
This article contains part of the results of the "Youth, Disaffiliation and Violence" extension project developed at the Institute of Psychiatry of the Federal University of Rio de Janeiro in 2008. It seeks to present experiences of violence experienced in three different contexts, namely in the family home, on the streets and in shelter units (SU), from the standpoint of adolescents. Thirty adolescents in five SUs in the municipality of Rio de Janeiro were interviewed. A qualitative approach was used in order to examine a relatively unknown reality, seeking a contextual understanding from the perspective of the social actors. To achieve this goal, this study sought the contribution of oral reports as the methodology for data collection. The theory of communication was the method of analysis, through the objective/ subjective narratives of experiences of adolescents, establishing categories and points of analysis that permeate these experiences. The results revealed that youths housed in shelters are exposed to various psychosocial risks related to violence experienced in the environments visited. Lastly, the need for setting up an intersectorial network aiming at providing effective and comprehensive care for adolescents was highlighted.
\end{abstract}

Key words Public Policies, Violence, Adolescence, Shelters, Psychosocial risks
Resumo Este artigo é parte do resultado do Projeto de Extensão Juventude, Desafiliação e Violência, desenvolvido no Instituto de Psiquiatria da Universidade Federal do Rio de Janeiro em 2008. Tem como objetivo apresentar, a partir da voz de adolescentes, experiências de violências vividas em três diferentes contextos: família, rua e unidades de acolhimento (UA). Foram entrevistados 30 adolescentes, que estavam abrigados em cinco UA, no município do Rio de Janeiro. Utilizou-se o enfoque qualitativo, a fim de explorar uma realidade pouco conhecida, buscando o entendimento contextual a partir da visão dos atores sociais. Para atingir o objetivo proposto, este estudo recorreu à contribuição da história oral, como metodologia para coleta dos dados, e à teoria da comunicação, como método de análise para articular, através das narrativas dos adolescentes, as vivências objetivas/subjetivas, estabelecendo categorias e pontos de análise que atravessam estas vivências. Os resultados apontaram que os abrigados estão expostos a diversos riscos psicossociais relacionados às violências vividas nos cenários abordados. Por fim, percebeu-se a necessidade do estabelecimento de uma rede intersetorial eficaz visando à integralidade da assistência aos adolescentes.

Palavras-chave Políticas públicas, Violências, Adolescência, Unidades de Acolhimento, Riscos psicossociais 


\section{Introdução}

A adolescência é um tema vastamente tratado na literatura científica, porém não existe consenso quanto à faixa etária que abarcaria essa fase da vida. Neste artigo elegeu-se a definição do Estatuto da Criança e do Adolescente (ECA) de que adolescente é a pessoa que tem idade entre 12 e 18 anos (art. 2) ${ }^{1}$, e que se encontra em processo de constituição psíquica de sua identidade, estando vulnerável a situações limites (art. 99, 100, 101)1.

Os adolescentes, foco deste artigo, encontravam-se abrigados em Unidades de Acolhimento (UA) do município do Rio de Janeiro. A faixa etária dos adolescentes girava em torno de 13 a 17 anos. A maioria tinha história de vida nas ruas, uso de drogas e de violência intrafamiliar e/ ou comunitária. Apresentava precariedade financeira, instabilidade/ fragilidade/ rompimento dos vínculos sociofamiliares, enfrentando grandes dificuldades para o restabelecimento dos laços sociais, ou seja, para sua reafiliação ${ }^{2}$ à sociedade.

Para Castel, o processo de desafiliação é uma "experiência de desengajamento social que quer dizer, o descolamento de regulações por meio das quais a vida social se reproduz e se reconduz"3. Já, para Bauman", estes desafiliados estão "fora do mundo da ordem e da pureza" e precisam ser removidos para longe da vista da sociedade estruturada. Como complicador desse contexto, as políticas públicas fundamentais costumam atuar sobre os efeitos, evitando as causas dos problemas $^{5}$. Elas poderiam auxiliar na reafiliação ${ }^{2}$, ou seja, na reintegração dos desafiliados à sociedade por meio da educação ou do trabalho com valor social.

A fonte deste artigo é o Projeto de Extensão Juventude, Desafiliação e Violência ${ }^{6}$ que pretendia estudar a atual rede de proteção/abrigamento e se esta representava uma "nova institucionalização" para os adolescentes. No transcorrer do Projeto, outros fatos singulares do funcionamento dessas instituições e outras circunstâncias da vida dos abrigados, mostraram-se importantes para serem investigados.

Deste modo, neste artigo, escolheu-se problematizar as violências e os riscos psicossociais trazidos nas narrativas dos adolescentes abrigados, para que se pudesse conhecer suas percepções sobre esses aspectos, ter contato com suas realidades e com suas formas de pensar. Partia-se do pressuposto que, ao recordar e narrar suas histórias, os entrevistados vivenciaram um encontro profundo com suas memórias e com suas questões subjetivas?.
As narrativas dos abrigados trouxeram, de forma recorrente, o tema violência, que Minayo descreve como sendo: "um termo muito complexo, sempre que falamos nela, estamos falando de relações desiguais, em que um tenta dominar, agredir física ou emocionalmente, ou ainda se omite de seu papel em relação ao outro. No caso das crianças, na medida em que os direitos à alimentação, ao vestuário, ao afeto e à proteção são negados ou violados, a violência está sendo praticada"s.

O Relatório Mundial da Violência da Organização Mundial da Saúde (OMS) ${ }^{9}$ apresenta três amplas categorias [de violência] de acordo com características do ato violento: a interpessoal, a coletiva e a autoproduzida. De acordo com este relatório, a violência pode ser física, sexual, psicológica, e que envolve maus tratos e negligência. Todavia, em estudos realizados desde 1999, com esses adolescentes, verificou-se a expressão de um tipo de violência, que se sobrepõe a todas as demais e que emerge das vozes destes sujeitos ${ }^{8}$. Denominada violência silenciosa ${ }^{10}$, tem como característica principal o fato de ser naturalizada por quem a sofre, quem a pratica e quem a observa. Bourdieu, assim, descreve tal violência: "[...] simbólica, violência branda, invisível, desconhecida como tal, tanto escolhida quanto suportada, a da confiança, da obrigação, da fidelidade pessoal, da hospitalidade, da dádiva, da dívida, do reconhecimento, da compaixão, de todas as virtudes às quais, em uma palavra, presta homenagem à moral da honra, impõe-se como o modo de dominação mais econômico, por ser mais adaptado à economia do sistema"11.

A violência silenciosa é encontrada no cotidiano das desigualdades sociais, na ausência de políticas públicas resolutivas e no vácuo existente entre a implantação de uma política pública e sua gestão. Está presente no dia a dia dos desafiliados, mina a saúde física e mental, e os coloca, cada vez mais, à margem da cidadania ${ }^{10}$.

$\mathrm{O}$ presente artigo apresenta material pouco explorado em estudos sobre adolescência, ao descrever, a partir da própria voz dos adolescentes, vivências que interferem na saúde e no sofrimento presentes nas relações socioassistenciais. Outras pesquisas qualitativas ${ }^{12-17}$ trouxeram as falas dos adolescentes a fim de compreender as violências nas perspectivas educacional, sociológica, psicológica ou etnográfica, não abordando diretamente esta violência, naturalizada, silenciosa, expressa nas entrevistas realizadas pelo Projeto de Extensão Juventude, Desafiliação e Violência ${ }^{6}$.

Os resultados abduzidos por este estudo serviram de base de argumentação para abrir espa- 
ços de interlocução com gestores municipais da assistência social e da saúde. Com efeito, puderam-se propor coletivamente mecanismos de intervenção que subsidiassem a estruturação e a disseminação de atitudes inovadoras nas UA, articuladas à promoção das políticas básicas, previstas em lei ${ }^{1}$. Isto ocorreu na continuidade de ações, que ainda vêm sendo realizadas por este grupo de pesquisa.

\section{Campo e método}

O Projeto de Extensão Juventude, Desafiliação e Violência ${ }^{6}$ foi aprovado pelo Comitê de Ética do IPUB/UFRJ. Ele se desenvolveu no ano de 2008 em cinco UA do Rio de Janeiro, quatro instituições do sistema de abrigamento da Secretaria Municipal de Assistência Social do Rio de Janeiro (SMAS) e uma ONG. Estas instituições funcionavam como casas de passagem, triagem e permanência, onde 30 adolescentes, entre 13 e 17 anos, se autoescolheram para serem entrevistados. Para que fosse realizado o processo de autoescolha, foi explicitado para os adolescentes do que se tratava o Projeto, quais eram os objetivos pretendidos, quem eram os pesquisadores e, finalmente, foram convidados a concederem entrevistas a fim de, basicamente, relatarem suas experiências dentro e fora das UA referentes à família, rua, unidade de acolhimento, escolarização e projetos de vida.

Os diretores das UA, que de acordo o art. 92, $\$ 1^{\circ}$ do $\mathrm{ECA}^{1}$, são equiparados a guardiões legais, para todos os efeitos de direito, assinaram termo de consentimento, livre e informado para cada adolescente, no momento das entrevistas. Os nomes dos entrevistados citados são fictícios para preservar o sigilo e a confidencialidade das informações. As entrevistas foram gravadas, transcritas e são apresentadas, em itálico, neste texto, da forma que eles falaram, podendo conter erros de português.

Utilizou-se o enfoque qualitativo, a fim de explorar uma realidade pouco conhecida, buscando o entendimento contextual a partir da visão dos atores sociais. Conforme afirmam Sampieri et al. ${ }^{18}$, os estudos de caráter qualitativo possuem característica indutiva. Tendo em vista que no campo de estudo analisado há carência de pesquisas, optou-se por uma pesquisa exploratória que, segundo Gil ${ }^{19}$, tem como principal objetivo desenvolver, esclarecer e modificar conceitos, pois visa o "desbravamento" do campo de pesquisa para provocar futuros estudos.
No que se refere à coleta do material, utilizouse o método da história oral, que, de acordo com Thompson $^{20}$, legitima e contextualiza a voz dos abrigados, que, ao narrarem suas vivências, puderam refletir sobre suas histórias de vida. Mesmo que apresentada em fragmentos, a memória oral traz evidências, revelando verdades não ditas e não presentes no registro oficial de um determinado contexto. Este método também possibilita coletar um conteúdo que advém de fontes inéditas, colocando os pesquisados como sujeitos de suas vidas ${ }^{21}$. Foi utilizado como instrumento, roteiro semi-estruturado ${ }^{22,23}$, a fim de abarcar questões gerais sobre família, rua, unidade de acolhimento, escolarização e projetos de vida, que pudessem fazer emergir o tema violência, em múltiplos contextos da vida dos entrevistados.

As entrevistas se estabeleceram no diálogo com aqueles que narraram suas memórias dentro e fora das instituições. Elas emergiram como lembranças soltas, muitas vezes incoerentes e conflitantes, já que eram vividas dentro do tempo psíquico, nem sempre real, trazendo aspectos objetivos e subjetivos $^{24}$, possibilitando aos pesquisadores levantarem dados relevantes de sofrimentos e riscos psicossociais.

Para a análise dos dados, empregou-se a teoria da comunicação, através do método da abdução, estudado por Boudon ${ }^{25}$. De acordo com o autor, o objetivo deste método é criar uma rede de sentidos, que podem revelar novas pistas, a partir do diálogo constante entre os argumentos e os contra-argumentos. O que o diferencia é o fato de não trabalhar com categorias pré-estabelecidas, mas com aquelas que vão sendo levantadas e construídas a partir das narrativas colhidas, pois evidenciam as estruturas de pensamento do narrador, de onde podem surgir fatos não claros à primeira vista. Mesmo sabendo que cada entrevista se refere a um sujeito singular, alguns elementos recorrentes, que emergiram de falas individuais, puderam ser agrupados e apresentados como um conjunto de fatores que podem vir a traduzir a vida social deste grupo de abrigados entrevistados, no período deste Projeto.

\section{Resultados e Discussão}

Pela delimitação de espaço, não foi possível incluir aqui toda a riqueza encontrada no material coletado. Deste modo, optou-se por focar nas vivências de violências, que geravam riscos psicossociais e afetavam a saúde mental dos acolhi- 
dos. Para este artigo escolheu-se três categorias para serem apresentadas: (1) família; (2) rua; (3) unidades de acolhimento (UA). As tabelas sintetizam os indicadores de duas categorias abordadas: a primeira apresenta os motivos de ida para as ruas, e a segunda indica a rotatividade dentro da rede de abrigos.

O Projeto Juventude, Desafiliação e Violência $^{6}$ pretendia estudar a atual rede de proteção/ abrigamento, e se esta representava uma "nova institucionalização" para os adolescentes. Por meio dos relatos, foi possível perceber que as UA reproduziam aspectos do modus operandis dos antigos internatos, cuja essência se caracterizava pelo assistencialismo paralelo à correção/repressão, sem levar em consideração o sujeito de sua ação. Apesar de o novo sistema ter libertado os adolescentes do internato fechado, esse não priorizou (1) o trabalho socioeducativo que pudesse facilitar a criação de vínculos necessários para o fortalecimento da estruturação psíquica e constituição da identidade adulta; (2) a articulação de uma rede intersetorial que oferecesse serviços de saúde, educação, cultura, esporte, lazer, geração de trabalho e renda, habitação, transporte e capacitação profissional, visando à integralidade da assistência ao adolescente ${ }^{26}$.

\section{Violências vividas na relação com a família}

O Brasil, em função do projeto de nação aqui implantado, "calcado em padrões europeus, numa ordem 'científica' e excludente de tudo o que fugisse da regra prevista e contrária aos verdadeiros interesses da maioria da população do país" 27 , tem sido marcado por desigualdades sociais. Uma consequência desta marca, entre tantas, são famílias, e, por conseguinte, adolescentes que se encontram fora do "mundo da ordem" Castel $^{2}$ faz uma "análise dos fatores contemporâneos de dissociação social", em que a desafiliação seria "um modo particular de dissociação do vínculo social". Dentre os fatores contemporâneos de dissociação social, a desafiliação seria um modo particular de precariedade financeira e fragilidade de relacionamentos sociais e profissionais. $\mathrm{O}$ extremo do processo de desafiliação é a miséria, o isolamento social e o desemprego, onde a precariedade financeira se tornaria "privação" e a "fragilidade relacional", isolamento ${ }^{2}$.

Segundo o autor, a desafiliação pressupõe a conjunção de dois eixos: primeiro, pela integração/não integração no trabalho; e segundo, pela inserção/não inserção na rede sociofamiliar. A partir destes dois eixos, o autor aponta que o indivíduo pode se encontrar numa gradação dentro do espaço social, dividindo-o em três zonas: integração, vulnerabilidade e desafiliação. A zona de integração está associada às relações estáveis no trabalho e na família; a de vulnerabilidade é uma zona intermediária, instável, que conjuga a precariedade no trabalho - trabalhadores temporários, subempregados ou informais - à fragilidade dos suportes de proximidade; por fim, a zona de desfiliação configura-se pela ausência de participação em todas as atividades produtivas e o isolamento das relações.

Essas três zonas se diferenciam em relação à coesão social e não exatamente à divisão econômica, ainda que a população dessas diferentes zonas possa encontrar dificuldades financeiras. Daí o autor propor três implicações: primeiro, as fronteiras entre as zonas são porosas, uma engorda a outra; segundo, existe uma compensação entre os eixos que se cruzam, ou seja, o indivíduo estando bem inserido comunitariamente compensaria a não integração no mundo do trabalho e vice-versa, caso esteja bem empregado, pode sobreviver fora do eixo familiar; terceiro, a dimensão econômica não é determinante, apesar de não poder ser um fator negligenciado. $\mathrm{O}$ modelo proposto por Castel $^{2}$ não é estático, pelo contrário, ele enfatiza que o indivíduo pode transitar nos vários níveis de afiliação/desfiliação. "Os indivíduos em situação de flutuação nessas zonas, dentro da estrutura social, é que povoam seus interstícios, não encontrando seu lugar determinado nesta estrutura”.

Os adolescentes que se encontravam abrigados em UA pareciam transitar entre a zona de vulnerabilidade e de desafiliação. Suas relações sociofamiliares encontravam-se fragilizadas, quando não rompidas. Zélia, por exemplo, falou sobre sua história de abrigamento e o papel de sua mãe nessa história:

Depois que saí do abrigo [que entrou com 10 dias de vida e saiu quando a mãe foi buscá-la aos 10 anos] minha mãe me tirou de lá e me abandonou! [...] A gente continuou morando lá perto do abrigo, num condomínio, com minha mãe. Ela ficou com um cara chamado Aldo, ele queria até me registrar, colocar até o sobrenome dele no meu, [ela fica em silêncio antes de continuar] e depois ela me largou. E me deixou com uma mulher lá do Recreio.

A violência praticada no contexto familiar, não somente física, sexual, psicológica, ou a que envolve maus tratos e negligência, mas também aquela que é naturalizada, que coloca o sujeito à 
margem, "é um fator de risco para o adequado desenvolvimento e a integração social de crianças e adolescentes" ${ }^{28}$. Para Winnicott, no desenvolvimento "o que nos interessa é a provisão do ambiente bem adaptado às necessidades do indivíduo em dado momento" ${ }^{29}$. No caso de Carla, o "fracasso ambiental"29,30 foi significativo. Ela fugiu da violência vivida em um ambiente que deveria protegê-la, como contou: Minha tia, ela queria que eu arranjasse dinheiro, queria que eu se vendisse pra arranjar dinheiro, pra comprar comida pra comer. Aí eu não quis.

Olivia, para escapar das surras da mãe, que tinha ciúmes dela com o namorado, procurou cobertura na casa de desconhecidos e acabou sofrendo outro tipo de abuso: Eu saí de casa de vez e fui morar na casa do cara do bar, [...] fiquei dormindo na casa dele, [...] 'dorme aqui perto de mim', ele falou, 'mas eu quero alguma coisa em troca, eu quero alguma coisa em troca', por ele ter me aceito. Foi aí que eu perdi a virgindade, [inaudível e fazendo um gesto com a mão] devagarzinho... aí, ele encaixou tudo, eu nunca tinha beijado na boca...

Outro exemplo apareceu na fala de Breno:

Minha família me discriminava muito, falava que eu ia dar pra bandido, pra maconheiro. Eu dei sim. Mas, se eu dei pra bandido, pra maconheiro, creio que eu vou dar pra trabalhador. Quando eu chegar lá em casa, lá na comunidade, eu vou poder entrar lá, com a cabeça erguida e a minha família olhar lá e ver como: 'Ele deu pra bandido, deu pra maconheiro, mas hoje ele tá sendo alguém na vida'. E é esse o meu sonho, chegar lá como marinheiro, eu vou ter que estudar muito pra ser marinheiro. Subir a comunidade lá, com aquela farda toda branca, maiorzão, é meu sonho.

Presume-se que Breno ambicionava ser marinheiro como um antídoto para a vergonha que a família tinha dele e o estigma que ela lhe impunha, como explicitou Gaulejac ${ }^{31}$ : "Há muita ambiguidade na solicitação a 'ser você mesmo'. Este convite contém, implicitamente, um modelo de conduta, um ideal de comportamento. E quanto mais este modelo é difícil de atingir, mais pode estigmatizar os que não chegam lá. Na separação entre este 'eu mesmo' que é preciso encontrar e a identidade que a sociedade lhe confere, o sujeito é convidado a fazer um trabalho para se transformar, 'se realizar". No entanto, seria muito difícil para ele conseguir "se realizar", não só pelas condições vividas junto à família, que não lhe proporcionava um ambiente "suficientemente acolhedor" para o processo de construção de sua maturidade e aumento da autoestima ${ }^{29,30}$, mas, também, pela falta de programas sociais que o incluísse de modo mais consistente na vida cidadã. $\mathrm{O}$ conjunto desses fatores pode propiciar a expressão da violência silenciosa.

Apesar de tantas dificuldades, $64 \%$ dos entrevistados demonstraram desejo de seguir o "modelo" familiar, de retornar para casa, ou de construir sua própria família. Segundo Bowlby ${ }^{32-34}, \mathrm{o}$ indivíduo, geneticamente, está constantemente buscando se vincular afetivamente, a fim de garantir seu desenvolvimento psicossocial. Assim, Leandro explicitou sua aspiração:

Quando eu completar dezoito anos, eu vou querer fazer minha casa e morar com meu filho [...] voltar a morar com a minha família e com os meus filhos, o Luan e a Beatriz.

\section{Violência e saúde mental nas ruas}

Dos 30 entrevistados, 20 adolescentes tiveram passagem pela rua (nove meninas e 11 meninos). $\mathrm{O}$ tempo de permanência variou entre dois dias, mais de uma vez, até três anos e cinco meses, ininterruptos. O mais jovem foi para rua com 13 anos $^{6,35}$. Os motivos referidos para sair de casa (Tabela 1) giraram em torno de três situações principais: desentendimento com a família, fugas dos abrigos e envolvimento com tráfico na comunidade de origem ${ }^{6,35}$. Uma descoberta significativa do estudo foi de que $30 \%$ dos jovens chegaram às ruas evadindo das UA, onde foram colocados para serem protegidos ${ }^{6,35}$.

Uma vez nas ruas, os jovens usavam recursos pessoais, recriando estratégias que envolviam liberdade, esperança, criatividade, sagacidade, "saber cair na rua", sempre atravessadas pelo lúdico ${ }^{6,27,35-38}$. Sérgio gostava mais de estar nas ruas, do que em casa. A rua: Tem um monte de coisa [pensando], tem praia [pensando], comprar doce, arrumar comida, quentinha. É baratinho, é um $R \$ 1,20$ ! Ficar dentro de casa é ruim!

Tabela 1. Razões de ida para as ruas.

\begin{tabular}{lc}
\hline \multicolumn{1}{c}{ Motivos } & \% de jovens \\
\hline Atritos com a família & 30 \\
Evasão do abrigo após ter sido abrigado & 30 \\
pela família/responsável & \\
Envolvimento com o tráfico & 15 \\
Violência física ou sexual em casa & 15 \\
Uso de drogas & 05 \\
Não informado & 05 \\
Total & 100
\end{tabular}

Fonte: Botelho $\mathrm{AP}^{35}$. 
Agregando espaço e tempo à sua identidade, as ruas não se instituíam, para eles, como um lugar público, mas, um espaço privado de constituição psíquica e social, onde formavam sua família da rua, com regras próprias e recursos individuais/ solidários para sobrevivência. Sérgio descreveu:

A gente arrumava feijão e dividia com o outro. Tinha um menino que ele andava comigo, um maior tempão, que ele é o meu irmão de rua, agora ele tá aqui na Praça Quinze. Quando eu for embora, eu vou levar ele pra minha casa.

Para serem aceitos nessa "família", eram "testados", segundo Ziraldo:

Primeiro, eles vê se a gente rouba coisas deles mermo, aí eu não peguei nada deles, aí deixaram andar com eles.

Dentre as vantagens das ruas, Vera citou:

Acho que a liberdade. Eu acho bom porque não tem nada pra se preocupar, só tem que sair andando, encontrar lugares assim.

Cláudio gostava de perambular pelas ruas:

Eu gosto é de andar na cidade.

$O$ medo da violência nas ruas também apareceu nas narrativas e Ana contou o que temia:

Tiro, bala perdida, gente de judiaria, de maldade com o outro. De noite, o negócio pega.

As drogas podiam ser a sedução das ruas, segundo Lana:

Às vezes eu ficava com vontade de usar droga, aí eu saía de casa. Eu via os outro usando, aí eu fui, peguei, experimentei, aí depois eu fiquei usando.

Considera-se que a fragilidade ou o rompimento das relações sociofamiliares suscita a busca por uma família na rua. Esta possibilita que o adolescente se sinta liberto de regras impostas pela família originária e pela sociedade. Assim, é possível transgredir, com o suporte do território afetivo que ele cria para si. Imagina-se ali protegido. Contudo, vive riscos à sua saúde física e mental, como o uso indiscriminado de drogas, o sexo não seguro, a afiliação a grupos do tráfico, $\mathrm{e}$, enfim, à delinquência ${ }^{6,12,14,27,35-38}$.

\section{Violência}

\section{na proteção/abandono nas UA}

A "nova institucionalização", questão inicial desta pesquisa, foi observada através da rotatividade vivida pelos abrigados dentro das UA. Eles relataram circular entre os dispositivos de acolhimento, na maior parte das vezes em função de regras diversas ali existentes. As razões mais comuns eram: a desobediência às regras institucionais, que os levavam às fugas para atividades de lazer (esporte/festas) ou namoros; dificul- dades em se manterem "abrigados" por muito tempo; e as transferências em função da faixa etária determinada para cada abrigo (Tabela 2). Sem explicitar as causas para suas transferências, Olívia enumerou algumas UA por onde passou:

Posso ir falando por nome? Vou falando e me lembrando: primeiro foi em um convento em $\mathrm{Ni}$ terói; numa casa num abrigo em Vargem Grande; já passei no abrigo em Santa Cruz; já fiquei em um abrigo chamado Amai na Chácara; já passei no abrigo Nossa Senhora do Carmo em Vicente de Carvalho; no Gonzaguinha; já passei no... As regras das UA não eram compreendidas pelos entrevistados. Cláudio tomava o acolhimento enquanto aprisionamento. Para ele, as regras que deveriam ser seguidas cerceavam a vida social fora daquele ambiente:

Sair daqui [do abrigo] é foda. Que isso? Dia de saída é só no sábado e poxa, até seis da tarde, depois, tem que chegar e não vai sair mais. As regras também produziam ambivalência. Zito sabia que precisava ser protegido em função das ameaças de morte que sofria na comunidade em que vivia:

Eu achava importante todos os adolescentes fazerem atividades [...] porque é bem melhor do que ficar parado. Tipo assim, na Casa de Passagem, sentado, esperando, sem poder fazer nada. O nome já diz, Casa de Passagem, tu sabe que não vai ficar ali, aí você não tá na tua casa, você não sabe pra onde que vai, aí tu entra em desespero, mais desespero do que tu já tá.

Vale ressaltar que nessa UA eles permaneciam no máximo 60 dias, as atividades internas eram ínfimas, e não tinham permissão para sair.

A ociosidade dentro das casas foi outro tema recorrente, como foi possível perceber na fala acima e na seguinte:

Tabela 2. Rotatividade dos jovens pelas Unidades de Acolhimento.

\begin{tabular}{cccc}
\hline $\begin{array}{c}\text { Número } \\
\text { Abrigos }\end{array}$ & $\begin{array}{c}\text { Não viveu } \\
\text { na rua }\end{array}$ & $\begin{array}{c}\text { Viveu } \\
\text { na rua }\end{array}$ & $\begin{array}{c}\text { Total de } \\
\text { jovens }\end{array}$ \\
\hline 1 & - & 1 & 1 \\
2 & 5 & 2 & 7 \\
3 & 1 & 4 & 5 \\
4 & 2 & 2 & 4 \\
5 & 1 & 4 & 5 \\
6 & - & 3 & 3 \\
7 & - & 3 & 3 \\
8 & 1 & 1 & 2 \\
Total & 10 & 20 & 30 \\
\hline
\end{tabular}

Fonte: Botelho AP ${ }^{35}$. 
A gente mesmo que procurava fazer alguma coisa. Escrever, pra passar o tempo. Porque não tem nada pra fazer e outra assim, na hora do almoço não pode ficar no quarto, acorda e ele fica trancado o dia todo. A gente almoça, tá com sono, às vezes quer dormir, não pode. Tem que deitar num banco lá fora ou no chão, não pode entrar no quarto, porque ele fica trancado.

Os abrigados podiam dormir fora do horário, mas não na cama ou no quarto. As UA têm regras e elas são necessárias para balizar o desenvolvimento dos adolescentes. No entanto, são a maior fonte de conflito entre os acolhidos e os que acolhem, uma vez que são definidas pelas equipes sem haver pactuação com os adolescentes. As regras precisariam fazer sentido para os acolhidos, para serem aceitas como algo positivo e estruturante. No entanto, no manejo cotidiano dentro das UA, essas regras são automatizadas. Dependendo do profissional que as transmite, elas oscilam entre permissivas e punitivas. Lana relatou seu mal-estar diante da arquitetura do prédio que era todo gradeado:

Abrigo, cheio de grade, parece uma prisão. [...] Quando eu cheguei, eu achei estranho, era totalmente diferente do outro abrigo [anterior].

O que poderia levar Lana a distinguir proteção de contenção seria o trabalho socioeducativo e os vínculos de confiança entre equipe e abrigados. Assim, ela poderia compreender as grades como defesa do perigo externo ${ }^{6,10,35}$.

A falta de confiança nos profissionais relatada nas entrevistas era reforçada por atitudes de desrespeito. A violência silenciosa era expressa em mínimos gestos, em atitudes incompreensíveis, produzida por aqueles que tinham a função de acolher e educar. Zélia assim relatou:

A diretora nunca tem tempo pra gente. É o maior sacrifício. Pra pedir pra falar com ela, ela diz que tá sempre em reunião, [a gente] volta de novo, ainda tá em reunião. Que reunião é essa, ela senta na mesa, come, lancha? Depois, quando acontece alguma coisa, você explica que queria avisar a ela e, elas não querem te entender e, depois tira um mês, dois meses de saída da gente [no fim de semana] $e$, você acaba se estressando. Aí, acaba falando coisa que não quer falar e acaba piorando a situação.

A alta circularidade observada, seja por violação das regras institucionais, por idade limite de permanência nas UA, ou por decisões judiciais, pode vir a contribuir para a ruptura, a descontinuidade do trabalho protetivo e a não resolutividade de um trabalho de reafiliação ${ }^{2}$ social; e a afetar a criação de laços, o processo de educação social e a garantia dos direitos fundamentais.
Caso os adolescentes, objetivo primeiro da existência das UA, fossem ouvidos em suas demandas, a proposta de Olavo certamente seria incorporada à rotina das UA: Uma coisa que precisa neste abrigo é, uma vez por semana, tem que ter alguém que converse com a gente, [...] o abrigo precisa conversar com a gente, ver o nosso pensamento e ajudar a gente, não é não?

Verificou-se que tanto os adolescentes quanto os educadores necessitavam de conversas permanentes, um trabalho de continuidade das relações, que exigiria espaço e tempo (objetivos e subjetivos), para estabelecer confiança mútua e vínculos que viessem a possibilitar a realização de um trabalho de reafiliação social.

\section{Considerações finais}

A rede de assistência social implementada pós-E$\mathrm{CA}^{1}$ destina-se a acolher, de forma temporária e provisória ${ }^{26}$, adolescentes que necessitam de proteção. As UA deveriam constituir cenários de referência para os adolescentes, tendo por finalidade colaborar com a reinserção sociofamiliar.

Pôde-se constatar, através das entrevistas realizadas pelo Projeto de Extensão Juventude, Deasfiliação e Violência ${ }^{6}$, e também através de outro trabalho ${ }^{10}$ desenvolvido por este grupo de pesquisa, dificuldade em cumprir a função efetiva de proteger e favorecer a construção de sujeitos, quando o objeto da atenção ainda é o adolescente com problemas, e não o sujeito de direitos. As equipes das UA evidenciaram despreparo no manejo com os adolescentes abrigados.

Também, pôde-se averiguar que as funções de educador social, cozinheira, motorista, serviços gerais são preenchidas sem um critério bem definido. Muitos chegam às UA porque se encontram desempregados e conhecem alguém que já trabalha lá. Após contratados, não recebem treinamento inicial para ter suporte no trabalho que irão executar. A "capacitação" é adquirida na prática, antes mesmo que a direção faça o primeiro contato e avalie o perfil do profissional e suas qualificações. A seleção para a entrada na equipe técnica também não segue um critério de especialização ou de desejo pessoal. Os profissionais são aprovados em concurso público e alocados nas UA, sem que os gestores levem em conta, minimamente, seu histórico profissional.

Portanto, o processo de entrada de profissionais nas UA contraria o documento Orientações Técnicas: Serviços de Acolhimento para Crianças e Adolescentes ${ }^{26}$, elaborado pelo Conselho Na- 
cional dos Direitos da Criança e do Adolescente (CONANDA) e pelo Conselho Nacional de Assistência Social (CNAS), visto que não há processo de recrutamento e de seleção baseado em um perfil, assim como não são considerados critérios para a devida ocupação dos cargos e para o apropriado desempenho de tarefas. De fato, parece não existir preocupação em assegurar que profissionais destinados a trabalhar com abrigados sejam devidamente qualificados e supervisionados a fim de dar conta de tarefa tão singular e complexa.

Os cuidadores (equipe técnica, educadores sociais, cozinheira, motorista, serviços gerais) além de não serem recrutados e capacitados adequadamente, deveriam ter acesso a uma supervisão com abordagem interdisciplinar em saúde e educação que lhes proporcionassem suporte à saúde mental. Essa supervisão poderia proporcionar equilíbrio emocional entre o patrimônio interno e as exigências/vivências externas, para que tivessem o manejo e cuidado necessários para a "reinserção familiar [...] e possibilitar a cidadania para esses sujeitos" ${ }^{\prime 39}$.

Acredita-se que reabilitação psicossocial (RPS) pode ser utilizada para instrumentalizar os cuidadores no manejo cotidiano com os adolescentes. Esta abordagem possibilita trocas comunicacionais entre indivíduos, habilitando-os para exercer, da melhor maneira possível, a cidadania. Na definição de Pitta: "Ela [RPS] é uma atitude estratégica, uma vontade política, uma modalidade compreensiva, complexa e delicada de cuidados para pessoas vulneráveis aos modos de sociabilidade habituais, que necessitam cuidados igualmente complexos e delicados" ${ }^{\prime 4}$. Para Saraceno ${ }^{41}$ a RPS envolve "a reconstrução da plena cidadania e da contratualidade, ou seja, da capacidade de negociação, de efetuar trocas em três grandes cenários: casa, trabalho e rede social".

Lancetti e Amarante ${ }^{42}$ asseguram que "nas novas diretrizes ocorridas na área da saúde nos últimos anos no plano mundial (até mesmo por recomendação da OMS), outros profissionais, especialmente os que operam na atenção primária e outras áreas, são convocados para intervir nos processos de reabilitação das pessoas que ouvem vozes, usam drogas de maneira suicida, sofrem angústias, violências e opressões graves. Cada vez menos se busca separar a saúde física da saúde mental". E deixam claro que "fazer saúde mental hoje é uma tarefa que compete a todos os profissionais de saúde" ${ }^{\text {"42. }}$.
Os investimentos na atenção psicossocial para esse grupo social já vem sendo alertado como fator para integração e desenvolvimento do país, como afirmou Lessa no início da década de 1990: "Além da questão ética, existe uma dimensão estratégica, porque tudo o que representar em degradação dessas faixas etárias irá ser devolvido, com juros acrescidos, ao corpo social do futuro" ${ }^{\prime 3}$.

Este artigo expôs a violência silenciosa (sobrepondo e se associando aos outros diversos tipos de violência) como emergiu das narrativas dos adolescentes e se mostrou presente, pela voz dos abrigados, no abandono e/ou proteção pela família, ruas e UA, nos recursos individuais, nos laços afetivos nem sempre construídos. Ela ainda pôde ser vista na "nova institucionalização", existente nos atuais dispositivos de proteção, levando os abrigados à dependência socioemocional da rede de assistência social após os 18 anos. Metade dos entrevistados declarou, em suas entrevistas, $\mathrm{o}$ desejo de continuarem de alguma forma institucionalizados, seja nas forças armadas, polícias ou trabalhando na própria rede de acolhimento. No dizer de Pedro Pelegrino, o processo formador nessas instituições "visa educar tentando abolir do sujeito sua diferença e, depois de concluído o processo, lançar este mesmo sujeito num mundo que exigirá dele o exercício de uma diferença para a qual está despreparado" ${ }^{\prime 4}$.

A experiência exitosa da intervenção nas UA, baseada em pressupostos da reabilitação psicossocial em um trabalho de mediação de conflitos, propiciada pela parceria entre IPUB/UFRJ e Secretaria Municipal de Assistência Social do Rio de Janeiro (SMAS), pôde fornecer elementos para evidenciar a necessidade de construção de uma rede intersetorial (em especial assistência social, saúde e educação) eficaz que tenha como objetivo à integralidade da assistência aos adolescentes, particularmente, a atenção psicossocial desses sujeitos, de modo a lhes dar possibilidades de constituir uma identidade adulta e desenvolver sua maturidade emocional com autonomia após os 18 anos.

Estudos adicionais deverão ser realizados para refinar temas e hipóteses apresentadas no presente artigo, como a integralidade das políticas públicas para investir na saúde mental dos profissionais e adolescentes que se encontram em ambientes onde medidas de proteção especial são efetivadas; ou mesmo a precarização do trabalho realizado por várias categorias nas Unidades de Acolhimento para adolescentes. 


\section{Colaboradores}

AP Botelho, MCMB Moraes e LC Leite participaram igualmente de todas as etapas de elaboração do artigo.

\section{Agradecimentos}

Ao CNPq, pelo apoio financeiro à esta pesquisa. À Pró-reitora de extensão da Universidade Federal do Rio de Janeiro pela concessão de bolsas para alunos de graduação que participaram da pesquisa.

\section{Referências}

1. Brasil. Lei n. 8.069, de 13 de julho de 1990, dispõe sobre Estatuto da criança e do adolescente (ECA). Versão atualizada em 2012. Rio de Janeiro: Cedeca RJ; 2012.

2. Castel R. Les métamorphoses de la question sociale. Paris: Fayard; 1995.

3. Castel R. Rupturas irremediáveis: sobre Tristão e Isolda. Lua Nova [periódico na internet] 1998; [acessado 2013 set 16]; (43): [p. 174]: [cerca de 11p.]. Disponível em: http://dx.doi.org/10.1590/S0102-64451998000100010.

4. Bauman Z. Mal estar na pós-modernidade. Rio de Janeiro: Jorge Zahar; 1998.

5. Minayo MCS. Politicas sociais para jovens do Rio de Janeiro: cadastro e análise de casos. Rio de Janeiro: Fiocruz; 1999.

6. Leite LC, coordenadora. Juventude, desafiliação e violência [impresso]. Rio de Janeiro: IPUB, UFRJ; 2007.

7. Alberti V. Ouvir contar: textos em história oral. Rio de Janeiro: FGV; 2004.

8. Minayo MCS. O contrário da violência é a cidadania [entrevista] - RJ - Brasil. SBP Notícias [periódico na Internet]. 1999 Out-Nov [acessado em 2007 jun 12]; (8): [p. 15 e 16]. Disponível em: http://www.sbp.com. br/show_item 2.cfm?id_categoria $=88 \&$ id_detalhe =2047\&tipo_detalhe $=$ s.

9. World Health Organization (WHO). World report on violence and health. Geneva: WHO; 2002.

10. Leite LC, coordenadora. Violência, juventude e saúde mental [impresso]. Rio de Janeiro: IPUB, UFRJ; 2011.

11. Bourdieu P. A produção da crença: contribuição para uma economia dos bens simbólicos. São Paulo: Zouk; 2002.

12. Leite LC, coordenadora. Evasão escolar, drogas, criminalidade: os descaminhos na adolescência e suas articulações com questões do sujeito [impresso]. Rio de Janeiro: IPUB, UFRJ; 2004.

13. Leite LC. Apresentação. In: Leite LC, Leite MED, Botelho AP, organizadores. Juventude, desafiliação e violência. Rio de Janeiro: Contra Capa; 2008. p. 13-21

14. Minayo MCS, Assis SG, Souza ER, Njaine K, Deslandes SF, Silva CMFP, Fraga PCP, Gomes R, Abramovay M, Waiselfisz JJ, Monteiro MCN. Fala galera: juventude, violência e cidadania. Rio de Janeiro: Garamond; 1999.

15. Carrano P. Juventudes e cidades educadoras. Petrópolis: Vozes; 2003.

16. Castro LR, Correa J. Juventude contemporânea: perspectivas nacionais e internacionais. Rio de Janeiro: Faperj, Nau; 2005.

17. Avanci J, Assis S, Oliveira R, Pires T. Quando a convivência com a violência aproxima a criança do comportamento depressivo. Cien Saude Colet 2009; 14(2):383394.

18. Sampieri RH, Collado CF, Lucio PB. Metodologia de Pesquisa. $3^{a}$ ed. São Paulo: McGraw-Hill; 2006.

19. Gil AC. Métodos e Técnicas de Pesquisa Social. São Paulo: Atlas; 1999.

20. Thompson P. A voz do passado: história oral. Rio de Janeiro: Paz e Terra; 2002.

21. Lozano JEA. Práticas e estilos de pesquisa na história oral contemporânea. In: Ferreira M, Amado J, organizadores. Usos e abusos da História Oral. $8^{\mathrm{a}}$ ed. Rio de Janeiro: FGV; 2006.

22. Minayo MCS. O desafio do conhecimento: pesquisa qualitativa em saúde. 9a ed. São Paulo: Hucitec; 2006. 
23. Halpern EE, Leite LMC. Representações de adoecimento e cura de pacientes do Centro de Dependência Química do Hospital Central da Marinha. Cien Saude Colet 2012; 17(4):1079-1089.

24. Gaulejac V. Histoire en heritage: roman familial et trajectoire sociale. Paris: Desclée de Brouwer; 1999.

25. Boudon P. Le reseau du sens. Bern: Peter Lang Verlag; 2002.

26. Conselho Nacional dos Direitos da Criança e do Adolescente, Conselho Nacional de Assistência Social (Conanda, Cnas). Orientações Técnicas: Serviços de Acolhimento para Crianças e Adolescentes. Distrito Federal: Conanda, Cnas; 2009.

27. Leite LC. A razão dos invenciveis. Rio de Janeiro: UFRJ; 1998.

28. Abranches CD, Assis SG. A (in)visibilidade da violência psicológica na infância e adolescência no contexto familiar. Cad Saude Publica 2011; 27(5):843-854.

29. Winnicott DW. Privação e delinquência. São Paulo: Martins Fontes; 2005.

30. Winnicott DW. A Família e o desenvolvimento do indivíduo. Belo Horizonte: Interlivros; 1980.

31. Gaulejac V. As origens da vergonha. São Paulo: Via Lettera; 2007.

32. Bowlby J. Apego. São Paulo: Martins Fontes; 1990.

33. Bowlby J. Cuidados maternos e saúde mental. São Paulo: Martins Fontes; 1995

34. Bowlby J. Formação e rompimento de laços afetivos. São Paulo: Martins Fontes; 1997.

35. Botelho AP. Mal-estar na cidade maravilhosa: juventude desafiliada, rua e saúde mental [dissertação]. Rio de Janeiro: IPUB, UFRJ; 2008.

36. Leite LC. Outros descaminhos da adolescência: jovens invencíveis ao controle social. In: Saggese E, Leite LC, organizadores. Da clínica à reabilitação psicossocial: manual de saúde mental de crianças e adolescentes. Cad do IPUB online 2011; [acessado 2012 jul 23]. Disponível em: http://www.ipub.ufrj.br/portal/ensino-e -pesquisa/publicacoes/ cadernos-ipub
37. Botelho AP, Silva SLF, Kassab MJ, Leite LC. Meninos de rua: desafiliados em busca de saúde mental. Psicol Estud [periódico na Internet] $2008 \mathrm{Abr}-J u n$ [acessado 2013 maio 8];13(2): [361-370]. Disponível em: http://www. scielo.br/pdf/pe/v13n2/a19v13n2

38. Leite LC. Meninos de rua: a infância excluída no Brasil. 5a ed. São Paulo: Atual; 2009.

39. Prefeitura Municipal do Rio de Janeiro: Secretaria $\mathrm{Mu}-$ nicipal de Assistência Social [acessado 2008 jun 05]. Disponível em: www.rio.rj.gov.br/smas/Qsequipe.html

40. Pitta A, organizadora. Reabilitação psicossocial no Brasil. São Paulo: Hucitec; 1996. p. 20.

41. Saraceno B. Reabilitação psicossocial: uma estratégia para a passagem do milênio. In: Pitta A, organizadora. Reabilitação psicossocial no Brasil. São Paulo: Hucitec; 1996. p. 13-18.

42. Lancetti A, Amarante P. Saúde mental e saúde coletiva. In: Campos GWS. Tratado de saúde coletiva. Rio de Janeiro: Fiocruz; 2006. p. 615.

43. Lessa C. Questões da pobreza e da miséria. In: Leite CL, organizadora. Brasil: nação sequestrada. Petrópolis: Vozes; 1990. p.664.

44. Pelegrino P. Apresentação. In: Altoé S, organizador. Menores em tempo de maioridade: do internato-prisão à vida social. Rio de Janeiro: USU; 1993. p. 16.

Artigo apresentado em 27/09/2013

Aprovado em 31/01/2014

Versão final apresentada em 10/02/2014 